\title{
Control of FLIP $\mathrm{L}_{\mathrm{L}}$ expression and TRAIL resistance by the extracellular signal-regulated kinase1/2 pathway in breast epithelial cells
}

\author{
R Yerbes ${ }^{1}$, A López-Rivas ${ }^{\star, 1}$, MJ Reginato ${ }^{2}$ and C Palacios ${ }^{\star, 1}$
}

Increased activation of the epidermal growth factor receptor (EGFR) is frequently observed in tumors, and inhibition of the signaling pathways originated in the EGFR normally renders tumor cells more sensitive to apoptotic stimuli. However, we show that inhibition of EGFR signaling in non-transformed breast epithelial cells by EGF deprivation or gefitinib, an inhibitor of EGFR tyrosine kinase, causes the upregulation of the long isoform of caspase-8 inhibitor FLICE-inhibitory protein (FLIP $\mathrm{L}_{\mathrm{L}}$ ) and makes these cells more resistant to the tumor necrosis factor-related apoptosis-inducing ligand (TRAIL). We demonstrate that the extracellular signal-regulated kinase (ERK)1/2 pathway plays a pivotal role in the regulation of FLIPL levels and sensitivity to TRAIL-induced apoptosis by EGF. Upregulation of FLIPL upon EGF deprivation correlates with a decrease in c-Myc levels and c-Myc knockdown by siRNA induces FLIP $\mathrm{P}_{\mathrm{L}}$ expression. FLIP $\mathrm{L}_{\mathrm{L}}$ upregulation and resistance to TRAIL in EGF-deprived cells are reversed following activation of an estrogen activatable form of c-Myc (c-Myc-ER). Finally, constitutive activation of the ERK1/2 pathway in HER2/ERBB2-transformed cells prevents EGF deprivation-induced FLIP $P_{L}$ upregulation and TRAIL resistance. Collectively, our results suggest that a regulated ERK1/2 pathway is crucial to control FLIPL levels and sensitivity to TRAIL in non-transformed cells, and this mechanism may explain the increased sensitivity of tumor cells to TRAIL, in which the ERK1/2 pathway is frequently deregulated.

Cell Death and Differentiation (2012) 19, 1908-1916; doi:10.1038/cdd.2012.78; published online 22 June 2012

Tumor necrosis factor (TNF)-related apoptosis-inducing ligand (TRAIL) is a ligand of the TNF family capable of inducing apoptosis in a wide variety of cancer cells upon binding to pro-apoptotic receptors, but with no effect in the majority of normal human cells tested. ${ }^{1}$ This unique characteristic of TRAIL is currently being exploited as a potential antitumor therapy. ${ }^{2}$ Activation of TRAIL receptors (TRAIL-Rs) leads to the formation of the death-inducing signaling complex (DISC), which includes the receptor itself, the adapter molecule Fas-associated death domain (FADD) and procaspase-8. ${ }^{3,4}$ Processing and activation of caspase-8 at the DISC leads to a cascade of apoptotic events resulting in cell death. At the DISC level, the apoptotic signal may be inhibited by cellular FLICE-inhibitory protein (cFLIP), the homolog of viral FLIP (vFLIP) in vertebrate cells. ${ }^{5}$ In most cells, cFLIP exists as two alternative spliced isoforms: FLIP $\mathrm{L}$, a homolog of caspase- 8 that lacks critical amino acids for proteolytic caspase activity, and CFLIP $_{\mathrm{S}}$, consisting only of two death effector domains (DED). ${ }^{5}$ Although the role of FLIP as an inhibitor of apoptotic signaling has been controversial, ${ }^{6,7}$ recent data indicate that heterodimerization of FLIP $_{L}$ with procaspase- 8 induces limited caspase-8 activation, preventing further transduction of the apoptotic signal. ${ }^{8}$ FLIP expression fluctuates in a cell-type-specific manner and in response to various stimuli, transcriptionally through the $\mathrm{NF}-\kappa \mathrm{B}$ pathway, ${ }^{9}$ and at the protein level via altered rates of proteasomal degradation, ${ }^{10}$ which makes it a versatile inhibitor of apoptotic responses mediated by death receptors.

Binding of epidermal growth factor (EGF) to its monomeric receptor (EGFR) activates homo/heterodimerization and selfphosphorylation on tyrosine residues, which are used by docking proteins to engage molecules involved in different signaling pathways. ${ }^{11}$ Activation of the Ras-dependent extracellular signal-regulated kinase (ERK)1/2 mitogen-activated protein kinase (MAPK) pathway by EGF in normal cells is required for efficient $G_{1}$ - to $S$-phase transition and for the control of cell proliferation. ${ }^{12}$ Upon activation, ERK $1 / 2$ translocates to the nucleus and phosphorylates the ternary complex factor, which in turn induces the transcription of immediate-early genes like $c$-Fos and $c-M y c .^{13,14}$ Prolonged ERK activation results in c-fos and c-myc phosphorylation, stabilizing these transcription factors and thereby promoting

\footnotetext{
${ }^{1}$ Centro Andaluz de Biología Molecular y Medicina Regenerativa (CABIMER), Consejo Superior de Investigaciones Científicas, Sevilla, Spain and ${ }^{2}$ Department of Biochemistry and Molecular Biology, Drexel University College of Medicine, Philadelphia, PA, USA

*Corresponding authors: A López-Rivas or C Palacios, Centro Andaluz de Biología Molecular y Medicina Regenerativa (CABIMER), Consejo Superior de Investigaciones Científicas, Avenida Americo Vespucio s/n, 41092 Sevilla, Spain. Tel: +34 954467997 or +34 954 467934; Fax: +34 954 461664; E-mail: abelardo.lopez@ cabimer.es (AL-R); E-mail: carmen.palacios@ cabimer.es (CP)

Keywords: ERK1/2; c-myc; FLIPL; TRAIL; apoptosis

Abbreviations: EGF, epidermal growth factor; EGFR, epidermal growth factor receptor; ERK, extracellular signal-regulated kinase; 4HT, 4-hydroxytamoxifen; MAPK, mitogen-activated protein kinase; TRAIL, tumor necrosis factor-related apoptosis-inducing ligand; TRAIL-R, TRAIL receptor; TNF, tumor necrosis factor; FADD, Fas-associated death domain; FLIP, FLICE-inhibitory protein; DISC, death-inducing signaling complex; MEK1, MAPK/ERK kinase 1; PI3K, phosphatidyl inositol 3-kinase

Received 11.1.12; revised 24.4.12; accepted 15.5.12; Edited by M Deshmuck; published online 22.6.12
} 
activation of the $\mathrm{G}_{1}$-specific cyclin-dependent kinases and cell cycle entry. ${ }^{15,16}$

In many human cancers, including breast carcinoma, EGFR overexpression is correlated with cellular proliferation, angiogenesis and tumor growth, leading to invasiveness and metastasis, ${ }^{17}$ thus providing a potential target for therapy. ${ }^{18}$ In several tumor cell types, activation of the EGFR induces resistance to different apoptotic stimuli, including TRAIL, ${ }^{19}$ due to activation of the phosphatidyl inositol 3-kinase (PI3K)/ AKT pathway. However, despite all the available evidences in tumor cells, the regulation of TRAIL sensitivity by EGFR signaling in non-tumor cells remains to be investigated. We report here that EGFR activation downregulates cFLIP expression and enhances the sensitivity of non-transformed human breast epithelial cells to TRAIL-induced apoptosis. Our results also indicate that cFLIP levels and TRAIL sensitivity are both controlled by the EGFR-mediated regulation of the ERK1/2 pathway and c-myc expression. In addition, we show that deregulated ERK1/2 activation in human breast epithelial cells transformed with the oncogene Her2/ERBB2 prevents EGF deprivation-induced FLIP $_{\mathrm{L}}$ upregulation and TRAIL resistance, underlining the relevance of this pathway in controlling TRAIL-induced apoptosis.

\section{Results}

EGF controls the sensitivity of human breast epithelial cells to TRAIL-promoted apoptosis at the apical level in TRAIL-R signaling. In the past years, several compounds targeting the EGFR have been developed to treat advanced cancers. ${ }^{18}$ Moreover, inhibition of EGFR signaling synergizes with TRAIL in the induction of apoptosis in tumor cells. ${ }^{20}$ However, cross-talk between EGFR and TRAIL-R signaling has not been investigated in non-tumor cells. To address this issue, we determined the effect of EGF deprivation on the apoptotic response to TRAIL in non-tumor breast epithelial cell lines. Results depicted in Figure 1a and Supplementary Figure S1A and S1C demonstrate that preventing EGFR signaling by EGF deprivation induced resistance to TRAIL. These results we confirmed with gefitinib, an inhibitor of the EGFR tyrosine kinase and EGFR signaling. ${ }^{21}$ Incubation of MCF10A cells in EGF-containing medium (CM) with gefitinib completely inhibited TRAILinduced apoptosis (Supplementary Figure S2A), further indicating that EGFR activation facilitates TRAIL-induced apoptosis in non-tumor cells.

Activation of pro-apoptotic receptors by TRAIL induces apical procaspase-8 cleavage to generate the small subunit, p12, and the p43/41 intermediate fragment, which is subsequently processed to produce the large catalytically active $p 18$ subunit. ${ }^{4}$ We determined the processing of procaspase- 8 in MCF10A cells treated with TRAIL following culture of cells in the presence or absence of EGF. Procaspase-8 cleavage to generate its $43-41 \mathrm{kDa}$ intermediate fragments, and the subsequent generation of $\mathrm{p} 18$ subunit upon TRAIL-R activation were markedly inhibited in MCF10A cells deprived of EGF (Figure 1b).

Upregulation of FLIP $\mathrm{L}_{\mathrm{L}}$ upon EGF deprivation confers resistance to TRAIL. Expression levels of DISC proteins such as TRAIL-R2, FADD or procaspase-8 did not change following EGF deprivation in MCF10A cells (Figures 1c and d), indicating that a reduction of pro-apoptotic DISC components was not the mechanism underlying the diminished caspase-8 activation by TRAIL in EGF-deprived cells. Interestingly, EGF withdrawal caused the upregulation of the a

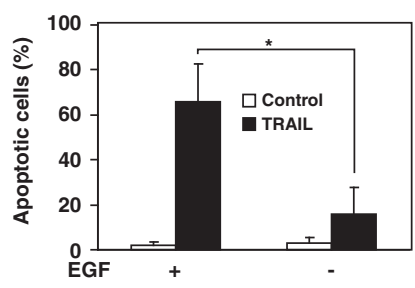

C

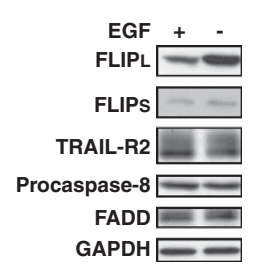

d

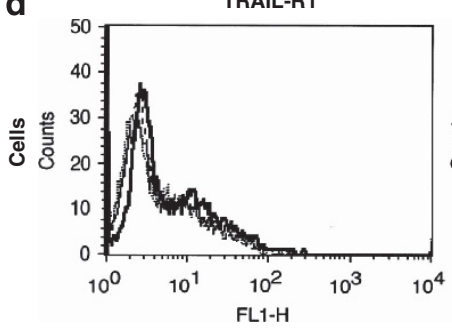

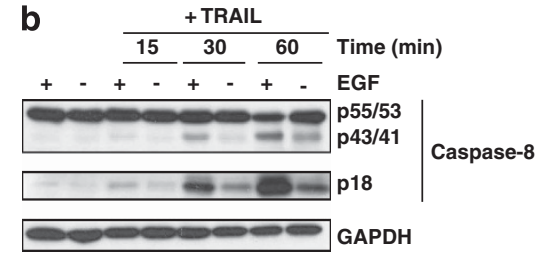

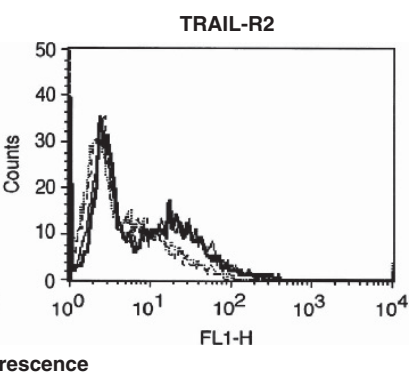

Figure 1 EGF deprivation induces resistance to TRAIL-induced apoptosis at the apical level. (a) MCF10A cells grown in the presence or absence of $20 \mathrm{ng} / \mathrm{ml}$ EGF during $48 \mathrm{~h}$ were treated with or without TRAIL $(500 \mathrm{ng} / \mathrm{ml})$ for $6 \mathrm{~h}$. Apoptosis was then measured as described in Materials and Methods. Error bars represent S.D. from three independent experiments. ${ }^{*} P<0.05$. (b) MCF10A cells were grown in the presence or absence of EGF for $48 \mathrm{~h}$ before adding TRAlL $(1 \mu \mathrm{g} / \mathrm{ml})$. Cells were incubated with TRAIL for the indicated times and activation of caspase-8 was assessed by western blotting. In the TRAIL-untreated samples, FLIP, , FLIP , TRAIL-R2, procaspase-8 and FADD levels were also determined. (c) Glyceraldehyde-3-phosphate dehydrogenase (GAPDH) was used as a protein loading control. Results are representative of two independent experiments. (d) Cells incubated with $(-)$ or without EGF $(-)$ for $48 \mathrm{~h}$ were harvested and cell surface expression of TRAIL-R1 and TRAIL-R2 receptors assessed by flow cytometry as described in Materials and Methods. Cells incubated with FITC-labeled secondary antibody alone were used as a control for background

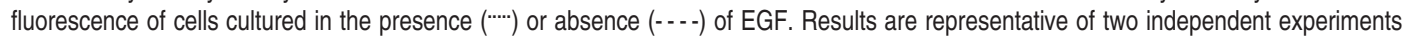


long form of cFLIP (FLIP $)$ in non-transformed breast epithelial cells (Figure $1 \mathrm{C}$ and Supplementary Figures S1B and S1D), suggesting a possible role of this inhibitor in the enhanced resistance to TRAIL of cells deprived of EGF. Furthermore, inhibition of EGFR signaling with gefinitib markedly upregulated FLIPL expression in MCF10A cells (Supplementary Figure S2B), confirming that EGFR activation by EGF is involved in the regulation of FLIP $P_{L}$ levels in non-transformed breast epithelial cells. In contrast, deprivation of either insulin or hydrocortisone, two medium additives for optimal growth of MCF10A cells, ${ }^{22}$ did not upregulate FLIP $\mathrm{P}_{\mathrm{L}}$ expression (Supplementary Figure S2C).

Time-course analysis of FLIP $\mathrm{L}_{\mathrm{L}}$ levels following EGF deprivation (Figure 2a, left panel) indicated that FLIP $_{L}$, but not FLIP , markedly accumulated in MCF10A cells between 40 and $72 \mathrm{~h}$ after EGF removal. FLIP $\mathrm{P}_{\mathrm{L}}$ levels slightly increased after $72 \mathrm{~h}$ incubation in the presence of EGF (Figure 2a, right panel), which was associated to a reduction in EGFR signaling as determined by the inhibition of ERK1/2 phosphorylation, most likely reflecting the impact of cell density on
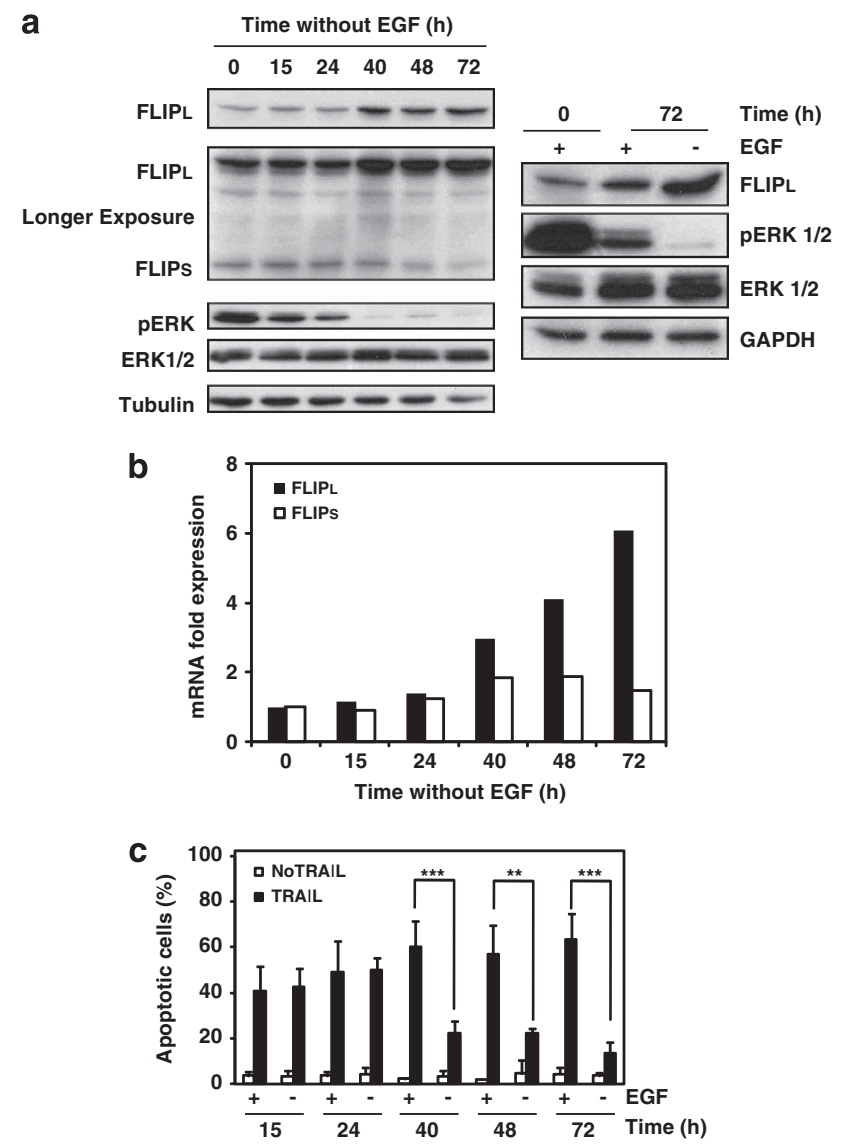

Figure 2 Upregulation of $F L I P_{L}$ upon EGF deprivation correlates with resistance to TRAIL. Analysis by western blotting (a) or quantitative PCR (b) of FLIP $L$ and FLIP levels in MCF10A cells deprived of EGF for the indicated times. The relative FLIP $P_{L}$ and FLIP $S$ mRNA expression for each time was plotted. Results are representative of three independent experiments. (c) MCF10A cells incubated in the presence or absence of EGF for the indicated times were treated with TRAIL $(500 \mathrm{ng} / \mathrm{ml})$ for $6 \mathrm{~h}$ and apoptosis was then determined as described in Materials and Methods. Error bars represent S.D. from three independent experiments. ${ }^{* \star} P<0.01,{ }^{* *} P<0.001$
EGFR signaling as reported recently. ${ }^{23}$ We next determined whether the upregulation of FLIP $\mathrm{L}$ protein seen in EGFdeprived cells was also observed at the mRNA level. RT-qPCR analysis of mRNA levels demonstrated that EGF deprivation induced a marked upregulation of FLIP $P_{L}$ mRNA starting at $40 \mathrm{~h}$ after EGF withdrawal (Figure $2 \mathrm{~b}$ ). Strikingly, a strong correlation was observed between the decrease in EGFR signaling (ERK1/2 phosphorylation) and the increased expression of FLIP $\mathrm{P}_{\mathrm{L}}$ and resistance of MCF10A cells to TRAIL following EGF deprivation (Figures $2 a$ and $c$ ).

As FLIP levels are important determinants of the sensitivity of breast tumor and non-tumor epithelial cells to TRAILinduced apoptosis, ${ }^{24,25}$ we then assessed whether silencing FLIPL expression could sensitize EGF-deprived cells to TRAIL. Interestingly, FLIP $\mathrm{L}_{\mathrm{L}}$ knockdown (Figure 3a, upper panel) was sufficient to prevent the induction of TRAIL resistance in EGF-deprived cells (Figure 3a, lower panel), indicating the importance of FLIP $_{\mathrm{L}}$ accumulation in the acquired resistance to TRAIL after EGF withdrawal. Furthermore, in cells stably overexpressing FLIP $_{\mathrm{L}}$ (Figure 3b, upper panel), TRAIL-induced apoptosis was clearly inhibited in EGF-CM (Figure 3b, lower panel). Our results supported an important role of EGF-regulated FLIP $P_{L}$ levels in the resistance of non-transformed breast epithelial cells to TRAIL-induced apoptosis.

Role of the ERK1/2 pathway in the control of FLIP $P_{L}$ levels and TRAIL resistance in breast epithelial cells. Upon EGFR activation by EGF, the MAPK/ERK and the PI3K/Akt pathways, among others, are activated to produce a physiological outcome. ${ }^{11}$ To investigate the role of these
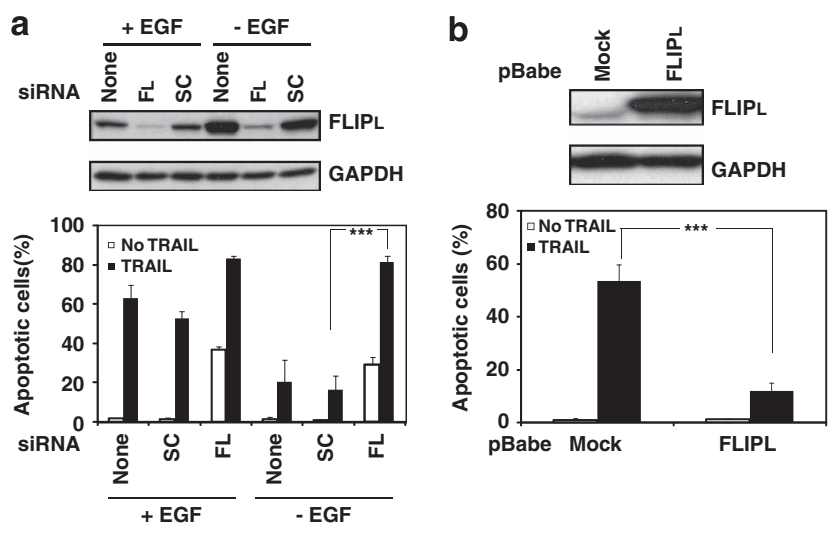

Figure 3 Role of $F L I P L$ in EGF deprivation-promoted resistance to TRAIL-induced apoptosis. (a) MCF10A cells were transfected either with a small interfering RNA (siRNA) oligonucleotide targeting $\mathrm{FLIP}_{\mathrm{L}}(\mathrm{FL}$ ) or a scrambled (SC) oligonucleotide for $24 \mathrm{~h}$ as described in Materials and Methods. Thereafter, cells were incubated in the presence or absence of EGF for $24 \mathrm{~h}$ before treatment with soluble TRAIL $(500 \mathrm{ng} / \mathrm{ml})$ for $6 \mathrm{~h}$. Apoptosis was measured as in Figure 1. Error bars represent S.D. from three independent experiments. ${ }^{* \star} P<0.001$. FLIP knockdown was assessed by western blotting and glyceraldehyde-3-phosphate dehydrogenase (GAPDH) was used as a protein loading control. (b) MCF10A cells were infected with retroviruses encoding control vector (pBabe Mock) or FLIP $\mathrm{L}_{\mathrm{L}}$. Following puromycin selection for stably infected cell lines, cells were treated with soluble TRAIL $(500 \mathrm{ng} / \mathrm{ml})$ for $6 \mathrm{~h}$ in the presence of EGF. Apoptosis was measured as in Figure 1. Error bars represent S.D. from three independent experiments. ${ }^{* * *} P<0.001$. FLIP $\mathrm{L}$ levels were assessed by western blotting and GAPDH was used as a protein loading control 
pathways in the control of FLIP $\mathrm{P}_{\mathrm{L}}$ levels, we assessed the effect of the inhibitors U0126 (MAPK pathway) and LY294002 (PI3K/Akt pathway) on the regulation of FLIP levels by EGF. Re-addition of either EGF-CM or EGF alone to EGF-deprived cells induced a marked downregulation of FLIP $\mathrm{L}_{\mathrm{L}}$ expression in MCF10A cells (Supplementary Figure S2D). Downregulation of FLIP $P_{L}$ after re-addition of $C M$ to EGF-deprived cells was not blocked by LY294002 (Figure 4a), although AKT was significantly inhibited, which indicated that the PI3K/Akt pathway was not involved in FLIP $_{L}$ regulation by EGFR signaling in MCF10A cells. In contrast to the lack of involvement of the PI3K/Akt pathway in the regulation of FLIP $P_{L}$ expression by EGF, the results depicted in Figure 4b (upper panel) and Supplementary Figure S1B and S1D demonstrated that the ERK1/2 pathway played an important role in the downregulation of FLIP expression following EGFR activation in several non-tumor breast epithelial cell lines. Thus, inhibition of the ERK1/2 pathway by the MAPK/ERK kinase 1 (MEK1) inhibitor U0126 blocked FLIP $\mathrm{L}_{\mathrm{L}}$ downregulation induced by EGF re-addition to EGF-deprived cells. Levels of the pro-apoptotic BH3-only protein BimEL levels are shown as control of a protein negatively regulated by the ERK1/2 pathway in these cells. ${ }^{26}$

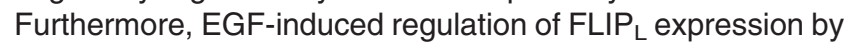
the ERK1/2 pathway occurred also at the mRNA level, as the presence of U0126 during EGF re-addition to EGF-deprived cells blocked, at least in part, FLIP $\mathrm{L}_{\mathrm{L}} \mathrm{mNA}$ downregulation (Figure 4b, lower panel). Importantly, inhibition of the ERK1/2 pathway prevented the restoration of sensitivity to TRAIL upon EGF re-addition to EGF-deprived cells (Figure 4c and Supplementary Figure S1A).
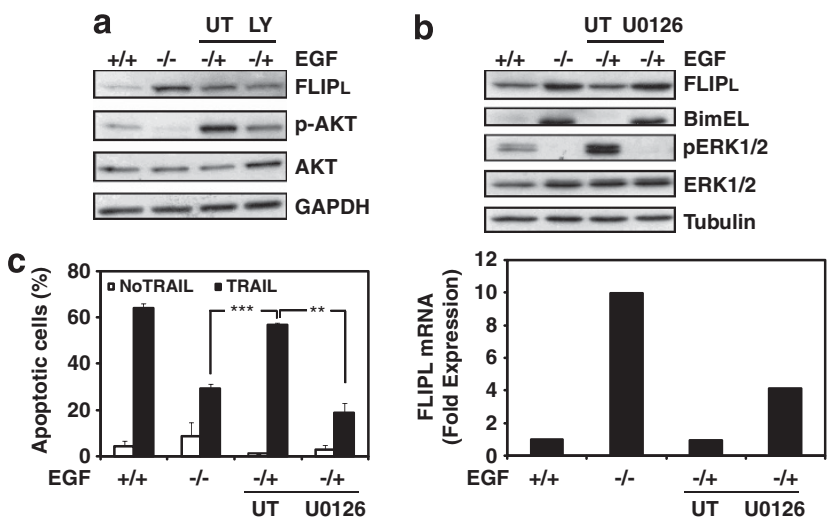

Figure 4 Inhibition of the ERK1/2 pathway prevents $F_{L I P}$ downregulation and sensitivity to TRAIL induced by EGF. MCF10A cells were preincubated in the absence of EGF for $48 \mathrm{~h}$ before re-addition of EGF $(-1+)$ and incubated in the presence or absence of (a) the PI3K inhibitor LY294002 (LY, $10 \mu \mathrm{M})$, or (b) the MEK1 inhibitor U0126 (10 $\mu \mathrm{M})$, for $15 \mathrm{~h}$. Other cultures were incubated in parallel with $(+/+)$ or without $(-/-)$ EGF for the entire experimental period (preincubation/incubation). FLIPL, p-AKT, AKT, p-ERK1/2, ERK1/2 and BimEL levels were assessed by western blotting. GAPDH and tubulin levels were used as protein loading controls. FLIP $\mathrm{mRNA}$ levels were measured by quantitative PCR (b, lower panel). Results are representative of two independent experiments. (c) Cells were preincubated/incubated as in (b) and then TRAlL $(500 \mathrm{ng} / \mathrm{ml})$ was added to some cultures for $6 \mathrm{~h}$. Apoptosis was determined as described in Materials and Methods. Error bars represent S.D. from three independent experiments. ${ }^{* \star} P<0.01,{ }^{* *} P<0.001$
To further demonstrate the role of the ERK1/2 pathway in EGFR-mediated regulation of FLIP $_{L}$ expression, we generated MCF10A cells overexpressing a constitutively active form of MEK1 (CAMEK1). As compared to mocktransfected cells, CAMEK1 cells maintained ERK1/2 phosphorylation after $48 \mathrm{~h}$ in the absence of EGF (Figure 5a). Interestingly, EGF deprivation did not result in the upregulation of FLIP $\mathrm{P}_{\mathrm{L}}$ in CAMEK1 cells, further supporting an inhibitory role of the ERK1/2 pathway in the regulation of FLIP expression. Finally, we examined whether the EGFRmediated regulation of sensitivity to TRAIL was altered in cells stably overexpressing CAMEK1. As shown in Figure 5b, CAMEK1 cells, which maintained low cellular levels of FLIP even in the absence of EGF in the culture medium, were

a
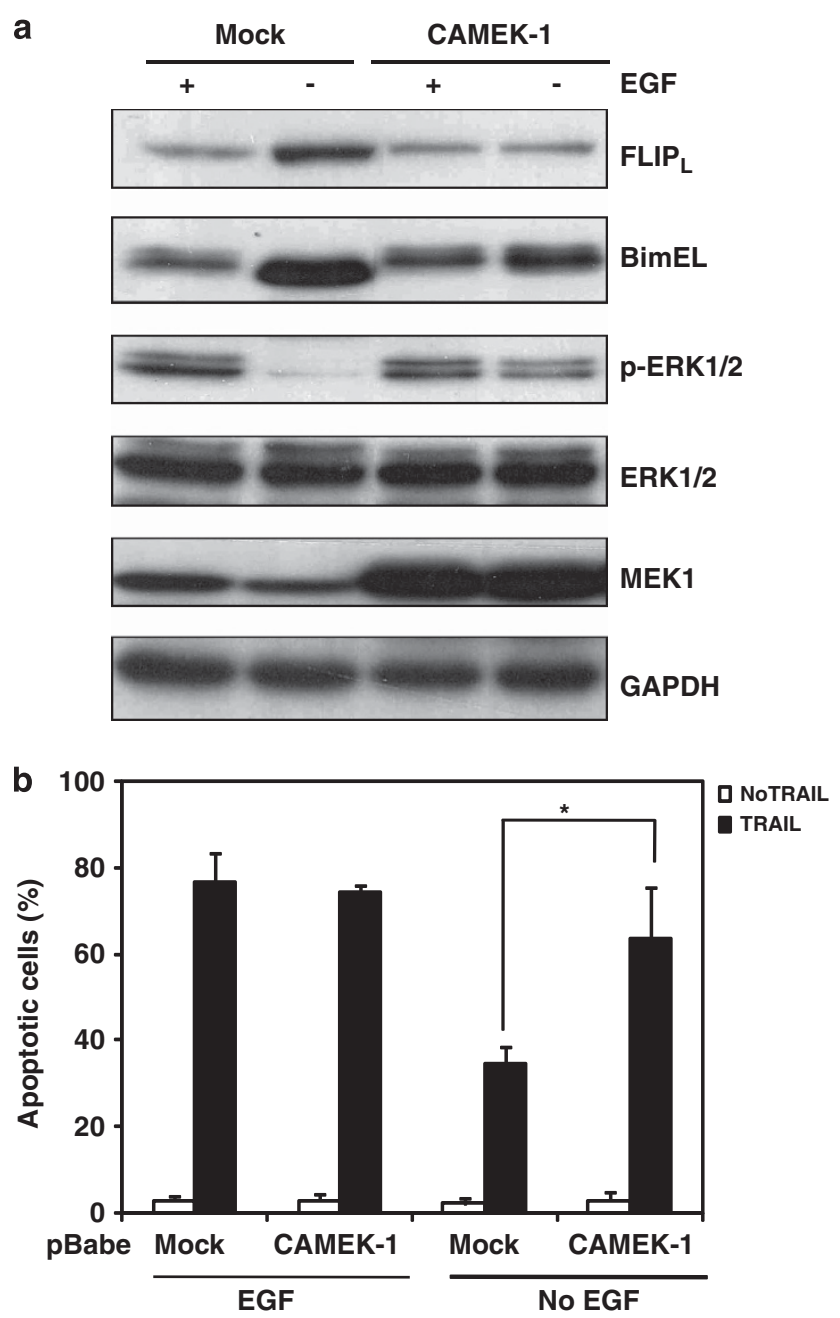

Figure 5 Constitutive activation of the ERK1/2 pathway abrogates EGFdependent regulation of FLIP levels and sensitivity to TRAIL. (a) MCF10A cells were infected with retroviruses encoding control vector (pBabe Mock) or a CAMEK1. Following puromycin selection for stably infected lines, cells were grown in the presence or absence of EGF for $48 \mathrm{~h}$, and phosphorylated ERK1/2, total ERK1/2, FLIP, BimEL and MEK1 levels were assessed by western blotting. GAPDH was used as a protein loading control. (b) Infected cells were incubated with or without EGF for $48 \mathrm{~h}$ before treatment with TRAIL ( $500 \mathrm{ng} / \mathrm{ml}$ ) for $6 \mathrm{~h}$. Thereafter, apoptosis was assessed as described in Materials and Methods. Error bars represent S.D. from three independent experiments. ${ }^{*} P<0.05$ 
sensitive to TRAIL-induced apoptosis independently of EGFR activation.

Role of c-myc in the control of FLIP $\mathrm{P}_{\mathrm{L}}$ levels in MCF10A cells by EGF. C-myc is a member of the Myc family of transcription factors that plays a central role in regulating cell growth, cell-cycle progression and apoptosis. ${ }^{27} \mathrm{C}$-myc is regulated at both transcriptional and post-transcriptional levels by the ERK1/2 pathway following activation of growth factors receptors. ${ }^{16,28}$ It has also been reported that c-myc could repress FLIP expression at the transcriptional level. ${ }^{29}$ To determine the role of c-myc in EGFR-mediated downregulation of FLIP $\mathrm{L}$ and sensitization to TRAIL-induced apoptosis, we first examined the regulation by EGF of c-myc protein levels in MCF10A cells. Results shown in Figure $6 \mathrm{a}$ indicate that EGF deprivation resulted in the inhibition of the ERK1/2 pathway and c-myc downregulation. Moreover, re-addition of EGF to EGF-deprived cells triggered the activation of the ERK1/2 pathway and the upregulation of c-myc in an ERK1/2-dependent manner, both events following an opposite pattern to FLIP $P_{L}$ levels. To further investigate

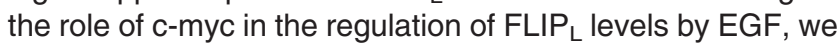
examined whether silencing c-myc expression could have an impact on FLIP $\mathrm{L}_{\mathrm{L}}$ levels in cells maintained in EGF-CM. Results shown in Figure $6 \mathrm{~b}$ indicate that c-myc knockdown

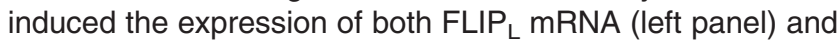
protein (right panel) in cells grown in the presence of EGF.

As a complementary approach to further demonstrate the role of c-myc in controlling FLIP $\mathrm{L}_{\mathrm{L}}$ expression in EGF-deprived cells, we generated MCF10A cells constitutively expressing an Myc-ER chimera. ${ }^{30}$ In these cells, activity of the chimeric myc protein is completely dependent on the addition of exogenous 4-hydroxytamoxifen (4HT). ${ }^{31}$ As a positive control of Myc-ER activation, we determined E2F-1 expression, a transcription factor positively regulated by $\mathrm{c}-\mathrm{myc}{ }^{32}$ in cells treated with $4 \mathrm{HT}$. As shown in Figure 6c, E2F-1 was upregulated following Myc-ER activation by $4 \mathrm{HT}$ in EGFdeprived cells. Interestingly, Myc-ER activation resulted in FLIP $\mathrm{P}_{\mathrm{L}}$ downregulation in MCF10A cells deprived of EGF, at both the protein and mRNA levels (Figure $6 \mathrm{c}$ ). Finally, we analyzed the sensitivity to TRAIL-induced apoptosis in cells in which Myc-ER was activated by $4 \mathrm{HT}$. Results shown in Figure 6d demonstrate that Myc-ER activation was sufficient to sensitize EGF-deprived cells to TRAIL.

Transformation blocks FLIP $P_{L}$ upregulation and TRAIL resistance upon EGF deprivation in MCF10A cells: role of the ERK1/2 pathway. To investigate the impact of cell transformation on the regulation of FLIP $_{L}$ expression and TRAIL sensitivity by EGF, we generated MCF10A cells that expressed a constitutively active form of the oncogene ERBB2/HER-2/neu. ${ }^{33}$ In cells overexpressing the ERBB2 (NeuT) protein, the ERK1/2 pathway was not inhibited upon EGF withdrawal (Figure 7a). Consistent with this finding, c-myc and FLIP levels did not change in response to EGF deprivation (Figure 7a). We next examined the regulation by EGF of TRAIL-induced apoptosis in both mock and NeuT-transduced cell lines. In contrast to what was observed in mock-transduced cells, EGF deprivation did not reduce the sensitivity to TRAIL in NeuT cells (Figure 7b), supporting the

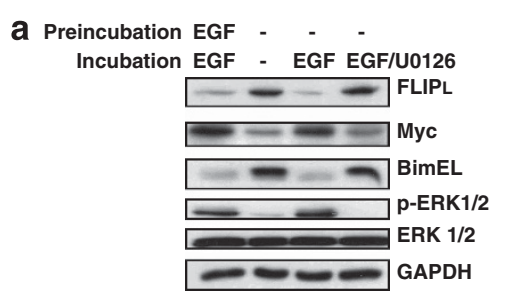

b
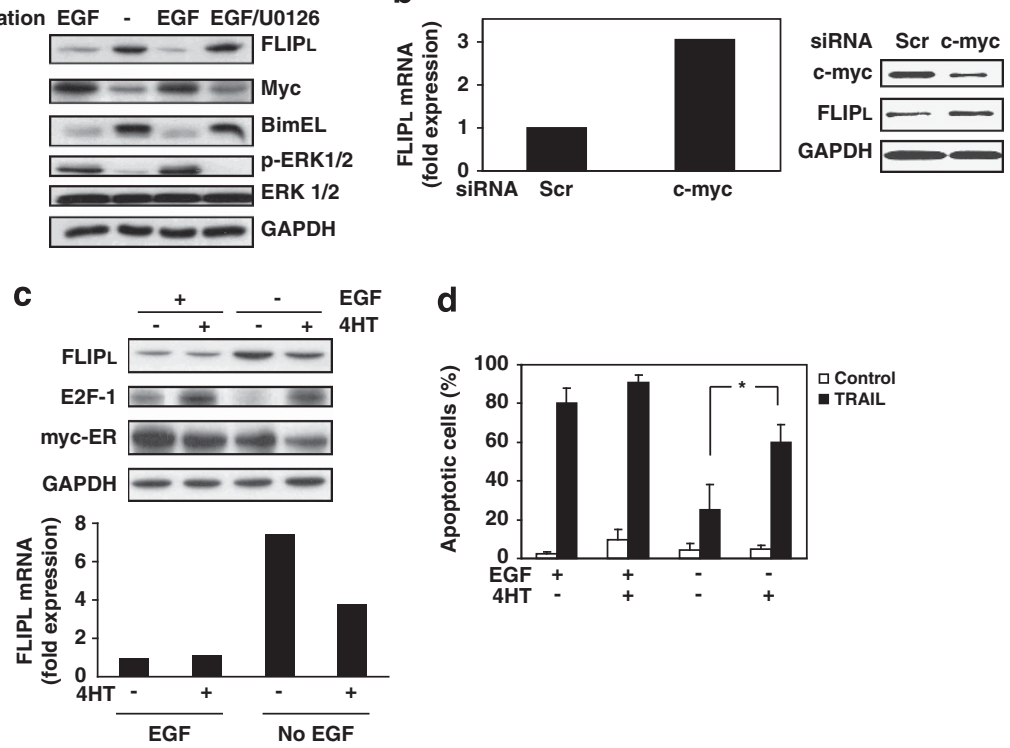

d

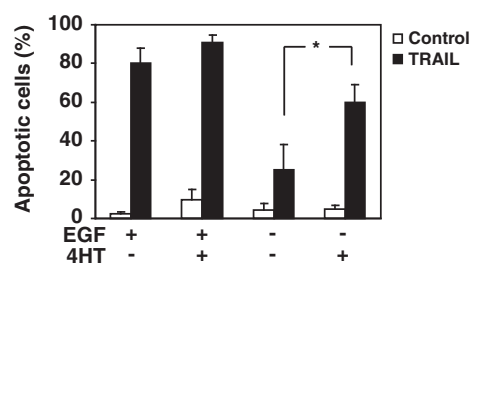

Figure 6 Role of c-myc in the control of FLIPL levels and TRAIL sensitivity by EGF. (a) MCF10A cells were cultured in the presence or absence of EGF during $48 \mathrm{~h}$, and then EGF was added for $24 \mathrm{~h}$ to EGF-deprived cells. P-ERK1/2, ERK1/2, c-myc and FLIP L levels (whole cell extracts) were analyzed by western blotting. GAPDH was used as a protein loading control. Results are representative of three independent experiments. (b) MCF10A cells were transfected either with a small interfering RNA (siRNA) oligonucleotide targeting c-myc or a scrambled oligonucleotide (Scr) for $48 \mathrm{~h}$ as described in Materials and Methods. FLIPL levels were assessed by quantitative PCR or western blotting. C-myc knockdown was analyzed by western blotting. Results are representative of three independent experiments. GAPDH was used as a protein loading control. (c) Cells stably expressing a c-Myc-ER chimera were cultured in the presence or absence of EGF for $48 \mathrm{~h}$ before incubation in the presence or absence of $4 \mathrm{HT}$ $(200 \mathrm{nM})$ for $30 \mathrm{~h}$. Upper panel shows the protein levels of FLIPL, E2F-1 and c-Myc-ER as measured by western blotting. GAPDH was used as a protein loading control. Lower panel shows the analysis by quantitative PCR of FLIP $P_{L}$ mRNA levels. Results are representative of three independent experiments. (d) c-Myc-ER cells treated as in (c) were incubated for $6 \mathrm{~h}$ with TRAIL $(500 \mathrm{ng} / \mathrm{ml})$ and apoptosis was determined. Error bars represent S.D. from three independent experiments. ${ }^{*} P<0.05$ 

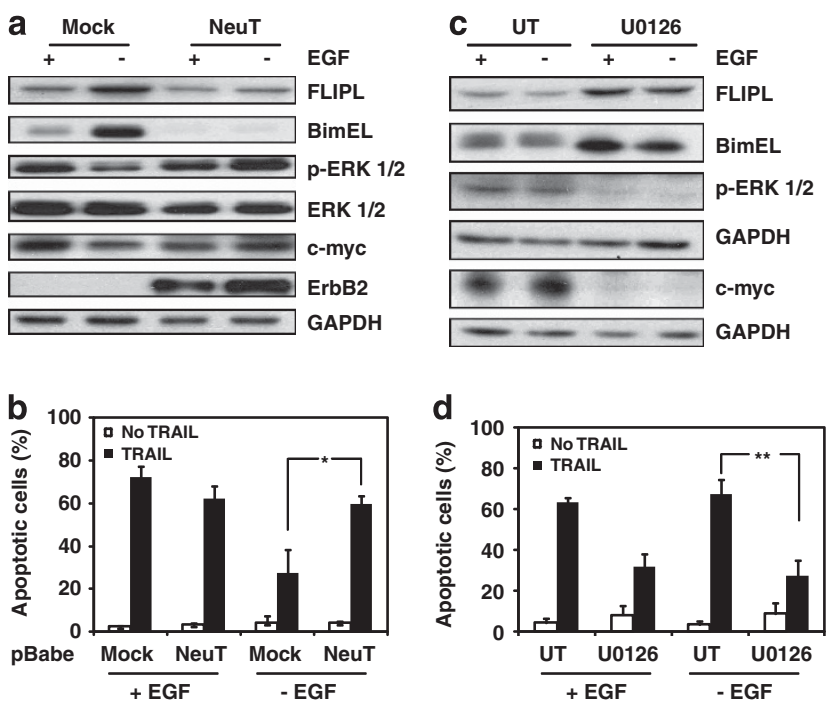

Figure 7 Oncogenic transformation blocks FLIPL upregulation and TRAIL resistance upon EGF deprivation in MCF10A cells. (a) MCF10A cells were infected either with a retroviral control vector (Mock) or a retrovirus encoding a constitutively active form of ERBB2 (NeuT). Following puromycin selection, cells were grown in the presence or absence of EGF during $48 \mathrm{~h}$ and FLIP , BimEL, ERK1/2, c-myc, ERBB2 and GAPDH levels and phospho-ERK $1 / 2$ status were analyzed by western blotting. Results are representative of three different experiments. (b) Infected cells were incubated as in (a) before adding TRAIL $(500 \mathrm{ng} / \mathrm{ml})$ for $6 \mathrm{~h}$. Apoptosis was measured as described in Materials and Methods. Error bars represent S.D. from three independent experiments. ${ }^{*} P<0.05$. (c) NeuT cells were incubated in the presence or absence of EGF for $32 \mathrm{~h}$. Following this incubation, the MEK1 inhibitor U0126 $(10 \mu \mathrm{M})$ was added to some cultures and the cells were incubated for $16 \mathrm{~h}$. Following this incubation, cells were either collected and protein levels analyzed by western blotting (c) or treated with TRAIL for $6 \mathrm{~h}$ to assess apoptosis (d). Error bars represent S.D. from three independent experiments. ${ }^{* \star} P<0.01$

hypothesis that the constitutive activation of the ERK1/2 pathway and c-myc expression in these cells are responsible for maintaining low FLIPL levels and sensitivity to TRAIL, independently of EGF supply. Furthermore, incubation of NeuT cells with the MEK1 inhibitor U0126 caused a marked inhibition of ERK1/2 phosphorylation and downregulation of c-myc expression (Figure 7c). Strikingly, U0126 treatment clearly upregulated FLIP $\mathrm{L}_{\mathrm{L}}$ expression (Figure 7c) and reversed transformation-mediated sensitivity to TRAIL (Figure 7d), independently of the presence of EGF in the culture medium.

\section{Discussion}

Preclinical studies conducted in the past years have demonstrated that TRAIL as well as agonistic antibodies against TRAIL-R1 and TRAIL-R2 can efficiently induce apoptosis in tumor cells, but not in the majority of normal cells. ${ }^{34,35}$ In many of these preclinical studies, TRAIL-sensitive cell lines were used and it has since become clear that some primary tumor cells are TRAIL resistant. ${ }^{36}$ Moreover, it has been reported that EGFR pathway activation limits TRAIL-induced apoptosis in breast tumor cells ${ }^{19}$ and the small-molecule EGFR inhibitor gefitinib reverses TRAIL resistance in other tumor cells. ${ }^{20}$ In this respect, there are ongoing clinical trials using combination of EGFR inhibitors and recombinant TRAIL. ${ }^{37}$ However, it is rather unknown the effect that these combination treatments may have in non-tumor cells. In our study, we demonstrate for the first time that preventing EGFR signaling induces resistance to TRAIL in non-tumor breast epithelial cells through the upregulation of FLIP $\mathrm{L}$ and inhibition of TRAILinduced apical caspase-8 activation. Our recently published data demonstrate that FLIP $\mathrm{L}_{\mathrm{L}}$ knockdown activates apoptosis by endogenous TRAIL in a DISC-dependent manner in the presence of EGF and reduces the number of acini in 3D basement-membrane cultures of MCF10A cells. ${ }^{25}$ Conversely, FLIP $\mathrm{L}_{\mathrm{L}}$ overexpression in MCF10A cells delays lumen formation in these cultures. ${ }^{25}$ In this respect, it has been reported that TRAIL is upregulated during morphogenesis of MCF10A mammary epithelial cells in 3D cultures and cooperates with $\mathrm{Bcl}-2$ family proteins to regulate lumen formation in MCF10A acini. ${ }^{38}$ During morphogenesis, the cells in the center of the epithelial mass lack matrix attachment, which leads to inhibition of EGFR signaling. ${ }^{26}$ In accordance with our results, it would be predicted that loss of EGFR signaling in the inner cells of the acini would induce FLIP $_{\mathrm{L}}$ expression and inhibit TRAIL-induced cell death. Collectively, these results suggest that maintenance of elevated FLIPL levels may have an important role in the timely control of morphogenesis in the mammary gland by preventing the early activation of TRAIL-induced cell death.

Of the signaling pathways activated upon engagement of tyrosine kinase receptors by their ligands, two of them, the PI3K/Akt and the MAPK/ERK pathways, are frequently reported to play a survival role preventing the induction of apoptosis. ${ }^{19,39}$ Furthermore, inhibition of $\mathrm{PI} 3 \mathrm{~K} / \mathrm{Akt}^{40}$ or MAPK/ERK ${ }^{41}$ increases the sensitivity of tumor cells to TRAIL-induced apoptosis. In contrast, other studies have shown that sensitivity to TRAIL can be enhanced upon activation of the $\mathrm{PI} 3 \mathrm{~K} / \mathrm{Akt}^{42}$ or ERK $1 / 2^{43}$ pathways, although the underlying mechanisms have not been characterized. We hereby report for the first time that in non-tumor human breast epithelial cells, activation of the ERK1/2 MAPK pathway by EGF is crucially involved in the sensitization of these cells to TRAIL-induced apoptosis. Most of the studies examining the regulation of TRAIL sensitivity by the PI3K/Akt and MAPK/ ERK pathways have been carried out in tumor cell lines of different sources in which these signaling pathways are commonly deregulated, leading to aberrant activation of genes involved in cell survival, metabolism, proliferation and migration. ${ }^{44}$ Moreover, it is well known that the number of active cell surface receptors for growth factors can determine whether ERK activation is transient or sustained, which results in markedly different cellular responses. ${ }^{45}$ Therefore, differences in cell surface EGFR levels may explain the different outcome of EGFR activation on FLIP levels and apoptosis sensitivity between normal and tumor cells.

Our results are in agreement with previous data indicating that sensitivity of EGF-dependent non-tumor breast epithelial cells to different apoptotic stimuli, including death receptor ligands, is abrogated in three-dimensional cultures (3D). ${ }^{46}$ In these 3D cultures, formation of a polarized structure is achieved and activation of the MAPK/ERK pathway by EGF is markedly attenuated. ${ }^{46,47}$ Whether or not FLIP ${ }_{L}$ levels increase in 3D cultures need to be investigated. Interestingly, non-polarized malignant breast epithelial cells maintain an elevated MAPK/ERK pathway activation in response to 
$\mathrm{EGF}^{47}$ and remain sensitive to death receptor ligands in 3D cultures. ${ }^{46}$

Through the phosphorylation of both cytoplasmic signaling proteins and transcription factors, activated ERK $1 / 2$ regulates cell metabolism, survival, differentiation, proliferation and migration. Among the transcription factors regulated by ERK, the ternary complex factor plays an important role in inducing the expression of immediate-early genes such as $c$-Fos and $c-$ Myc. $^{48}$ In addition, activation of the ERK $1 / 2$ pathway induces stabilization of the c-myc protein. ${ }^{49}$ Interestingly, our data demonstrate that EGF-dependent activation of the ERK1/2 pathway enhances c-Myc levels and negatively regulates FLIP $_{\mathrm{L}}$ expression in breast epithelial cells, and sensitizes these cells to TRAIL-induced apoptosis. By using either siRNA oligonucleotides to downregulate c-myc or the estrogen activatable Myc-ER chimera, we have provided further evidences supporting that c-myc plays a regulatory role in the control of FLIP $\mathrm{L}$ levels by EGF, which are in agreement with previous data indicating that c-myc binds and represses the human FLIP promoter and sensitizes cells to TRAIL. ${ }^{29}$ However, in tumor cells c-myc expression is frequently dissociated from the ERK1/2 pathway, either by mutation, reduced degradation through the ubiquitinproteasome system or by other mechanisms. ${ }^{49,50}$ Accordingly, in tumor cells FLIP levels could be regulated in an ERK1/2-independent manner by other survival pathways. ${ }^{51}$

Our results also indicate that in EGF-deprived cells, c-myc activation using a $4 \mathrm{HT}$-activatable Myc-ER chimera does not completely reproduce the sensitization achieved by EGF re-addition, which suggests that other effectors downstream of ERK1/2 activation could be also important for a complete apoptotic response to TRAIL. In this respect, it has been reported that $c$-Fos can function as a proapoptotic protein by repressing the expression of FLIP $\mathrm{L}_{\mathrm{L}}$ through binding to the gene promoter. ${ }^{52}$ Alternatively, other signaling emerging from the EGFR such as the p38-MAPK and the Jun N-terminal kinase (JNK) pathways might downregulate FLIP $\mathrm{P}_{\mathrm{L}}$ expression by transcriptional and post-transcriptional mechanisms. Thus, it has been demonstrated that EGFR-mediated activation of the p38 pathway regulates the activity of the transcription factor SP3, ${ }^{53}$ which under certain conditions could be a negative regulator of the FLIP ${ }_{L}$ gene promoter. ${ }^{54}$ Moreover, JNK activation by $T N F-\alpha$ reduces FLIP $_{L}$ stability by a mechanism involving the JNK-mediated phosphorylation and activation of the E3 ubiquitin ligase Itch, which ubiquitinates FLIP $\mathrm{L}$ and induces its proteasomal degradation. ${ }^{55}$

Overexpression of oncogenic receptor tyrosine kinases is a common event in breast cancer. In particular, $15-30 \%$ of all cases show elevated ERBB2, ${ }^{56}$ but despite the development of ERBB2/HER2-targeted therapies, only $35 \%$ of ERBB2positive patients initially respond to those treatments. It has been shown in experiments in vitro ${ }^{40}$ and in vivo ${ }^{57}$ that combination of antibodies against ERBB2 and TRAIL receptors facilitates apoptosis and tumor regression, although there are data reporting that the apoptosis-inducing capacity of these combinations is cell type-dependent. ${ }^{58}$ Our results indicate that in ERBB2-overexpressing cells sensitivity to TRAIL is controlled by the ERK $1 / 2$ pathway-mediated regulation of FLIP $\mathrm{P}_{\mathrm{L}}$ levels. These data suggest that amplification of ERBB2 in tumor cells may have different outcomes regarding sensitivity to TRAIL. On one hand, it may increase resistance to TRAIL through ERBB2-induced activation of the PI3K/Akt pathway. ${ }^{40}$ On the other hand, it may contribute to maintain low FLIPL levels by ERK1/2-mediated activation of c-myc and other genes, ${ }^{29,52}$ which may result in enhanced sensitivity to TRAIL. This is not unique of ERBB2 as other oncoproteins could also sensitize cells to TRAIL by activating the ERK1/2 pathway, ${ }^{59}$ although the mechanism underlying this sensitization has not been elucidated. Our data highlight the role of the EGF-regulated, ERK1/2 pathway-mediated regulation of FLIP $\mathrm{L}_{\mathrm{L}}$ levels as an important mechanism modulating the sensitivity of human breast epithelial cells to TRAIL-induced apoptosis that may contribute, in concert with others, to the differential sensitivity of normal and tumor cells to TRAIL. At the same time, our results provide arguments for a cautious clinical application of TRAIL in cancer patients, especially in combination with agents that may inhibit the ERK1/2 pathway.

\section{Materials and Methods}

Reagents and antibodies. Recombinant human EGF was from Peprotech (London, UK). Recombinant human TRAIL (residues 95-281) was produced as described previously. ${ }^{60}$ U0126 and gefitinib were purchased from Selleck Chemicals (Houston, TX, USA). Mouse anti- $\alpha$-tubulin antibody, LY294002, 4HT, hydrocortisone, transferrin and puromycin were obtained from Sigma-Aldrich (St. Louis, MO, USA). Anti-caspase-8 was generously provided by Dr. Gerald Cohen (Leicester University, Leicester, UK). Anti-FADD, anti-ERBB2 and antiE2F1 monoclonal antibodies were obtained from BD Biosciences (Erembodegem, Belgium). GAPDH and c-myc monoclonal antibodies were from Santa Cruz Technology (Santa Cruz, CA, USA). Anti-TRAIL-R2 and anti-c-FLIP monoclonal antibody (NF6) were from Alexis Corporation (Lausen, Switzerland). Anti-TRAILR1 and anti-TRAIL-R2 monoclonal antibodies for surface receptor analysis were from Abcam (Cambridge, UK). Anti-pAKT, anti-AKT, anti-pERK1/2 and anti-MEK1 antibodies were obtained from Cell Signaling Technology (Temecula, CA, USA). Anti-ERK antibody was from Upstate-Millipore (New York, NY, USA). Anti-Bim polyclonal antibody was purchased from Calbiochem (Darmstadt, Germany). Horseradish peroxidase or FITC-conjugated secondary antibodies, goat antimouse and goat anti-rabbit were obtained from DAKO (Cambridge, UK).

Cell lines. MCF10A and MCF12A cell lines were maintained in DMEM/F12 supplemented with $5 \%$ donor horse serum, $2 \mathrm{mM}$ L-glutamine, $20 \mathrm{ng}$ of EGF per $\mathrm{ml}, 10 \mu \mathrm{g}$ of insulin per ml, $100 \mathrm{ng}$ of cholera toxin per $\mathrm{ml}, 0.5 \mu \mathrm{g}$ of hydrocortisone per $\mathrm{ml}, 50 \mathrm{U}$ of penicillin per $\mathrm{ml}$ and $50 \mu \mathrm{g}$ of streptomycin per $\mathrm{ml}$ at $37^{\circ} \mathrm{C}$ in a $5 \%$ $\mathrm{CO}_{2}$-humidified, $95 \%$ air incubator. The $184 \mathrm{~A} 1$ cells were cultured in the same medium with transferrin $(5 \mu \mathrm{g} / \mathrm{ml})$.

Determination of apoptosis. Cells $\left(3 \times 10^{5}\right.$ per well) were treated in 6 -well plates as indicated in the figure legends. After treatment, hypodiploid apoptotic cells were detected by flow cytometry according to published procedures. ${ }^{60}$ Basically, cells were washed with phosphate-buffered saline (PBS), fixed in cold $70 \%$ ethanol and then stained with propidium iodide while treating with RNAse. Quantitative analysis of sub-G1 cells was carried out in a FACSCalibur cytometer using the Cell Quest software (Becton Dickinson, Mountain View, CA, USA).

Immunoblot analysis of proteins. Cells $\left(3 \times 10^{5}\right)$ were washed with PBS and protein content was measured following cell lysis using the Bradford reagent (Bio-Rad Laboratories, Hercules, CA, USA) before adding Laemmli sample buffer. Where indicated, whole cell extracts were obtained. Samples were sonicated, and proteins were resolved on SDS-polyacrylamide minigels and detected as described previously. ${ }^{60}$

Analysis of TRAIL receptors by flow cytometry. MCF10A cells were detached with RPMI/3 mM EDTA, and cytofluorimetric analysis of proteins was performed as described previously. ${ }^{60}$ Briefly, cells were washed in ice-cold PBS, and resuspended in PBS. Cells were then labeled with anti-TRAIL receptor antibodies ( $5 \mu \mathrm{g} / \mathrm{ml}$ ) or no antibody (negative control) and then incubated with goat 
anti-mouse FITC-conjugated antibody $\left(\mathrm{F}(\mathrm{ab})_{2}\right.$ fragment). Labeled cells were analyzed by flow cytometry using the Cell Quest software.

Real-time RT-PCR. Total RNA was isolated from MCF10A cells with the Trizol reagent (Life Technologies, Grand Island, NY, USA) as recommended by the supplier. Total RNA $(2 \mu \mathrm{g})$ was used as a template for CDNA synthesis using an RT-PCR kit (Perkin-Elmer, Waltham, MA, USA). mRNA expression was analyzed in triplicate by quantitative RT-PCR on the ABI Prism7500 sequence detection system using predesigned Assay-on-demand primers and probes (Applied Biosystems, Carlsbad, CA, USA). mRNA expression was determined by the comparative cycle threshold $\left(C_{t}\right)$ method $\left(\Delta \Delta C_{t}\right)$. Hypoxanthine-guanine phosphoribosyltransferase (HPRT Part Number 4331182 and HPRT1 Part Number 4351370) was used as an internal control and mRNA expression levels of FLIP $P_{L}$ and CFLIPs were given as fraction of mRNA levels in control cells. Primers and probes used were: CFLIP forward, $5^{\prime}$-CAGCAATCCAAAAGAGTCTCAAGGA-3'; cFLIPs reverse, $5^{\prime}$-AATTTTCAGATCAGGACAATGGGCATA-3'; probe FLIPS: 5'-ACTTCAGGATGATAACACCC-3'; for FLIP we used either of two different oligos and probes: FLIP $\mathrm{P}_{\mathrm{L}}$ forward, 5'-AGTGCCTCTCCCAGAAACTGA-3'; FLIPL reverse, 5'-GCTGTTCCAATCATACATGTAGCCATT-3'; probe FLIP $_{\text {L }}$, 5'-CAAGAAAGAAAACGCCCACTCC-3'; FLIPL 2 forward, 5'-GGCT CCCCCTGCATCAC-3'; FLIPL 2 reverse, 5'-TTTGGCTTCCCTGCTAGATAAG G-3'; probe FLIPL 2, 5'-CAGGAGGATGTTCATGGGAGATTCATGC-3'.

RNA interference. siRNAs against FLIP ${ }_{L}$ : 5'-CCUAGGAAUCUGCCUGAU AdTdT-3' and non-targeting scrambled siRNA were synthesized by Sigma Proligo (St. Louis, MO, USA). siRNA against c-Myc was purchased from Qiagen (Germantown, PA, USA) (FlexiTube). Cells were transfected with $50 \mathrm{nM}$ siRNAs using DharmaFECT-1 (Dharmacon, Lafayette, CA, USA) as described by the manufacturer. After $24 \mathrm{~h}$ for FLIP $\mathrm{L}$ siRNA or $48 \mathrm{~h}$ for c-myc siRNA, transfection medium was replaced with regular medium before further analysis.

Retroviral vectors and virus production. FLIP (in pCR3.V64 vector, a kind donation of Dr. J Tschopp, University of Lausanne) was cloned into BamHI/Sall sites of pBabepuro. pBabepuro constitutively active MEK (S217E/S221E) was a gift from Dr. CJ Marshall (Institute of Cancer Research, London, UK). pBabepuro-mycER was donated by Dr. J León (Instituto de Biomedicina y Biotecnología de Cantabria, Santander, Spain). Constitutively active ErbB2 mutant (pBabe-NeuT) was kindly provided by Danielle Carroll (Harvard Medical School, Boston, MA, USA). Retroviruses for protein overexpression were produced by transfection of HEK293-T cells by calcium phosphate method with the corresponding retroviral vectors. Retrovirus-containing supernatants were collected $48 \mathrm{~h}$ after transfection and concentrated by ultracentrifugation at 22000 r.p.m. for $90 \mathrm{~min}$ at $4^{\circ} \mathrm{C}$.

Generation of MCF10A cell lines. MCF10A cells were plated at $3.5 \times 10^{5}$ cells per $10-\mathrm{cm}$ dish and infected with the retroviruses mentioned above. Stable populations were obtained by selection with $1.5 \mu \mathrm{g} / \mathrm{ml}$ puromycin during $48 \mathrm{~h}$.

Statistical Analysis. All data are presented as the mean \pm S.D. of at least three independent experiments. The differences among different groups were determined by the Student's $t$-test. $P<0.05$ was considered significant.

\section{Conflict of Interest}

The authors declare no conflict of intrest.

Acknowledgements. We thank Dr. Gemma Fuster and Dr. Christophe Vandier for kindly providing us with the MCF12A and 184A1 cell lines, respectively. This work was supported by grants from Ministerio de Ciencia e Innovación (SAF2009-07163), Red Temática de Investigación Cooperativa en Cáncer (RTICC: RD06/0020/0068), the European Community through the regional development funding program (FEDER) and Junta de Andalucía (P09-CVI-4497) to ALR. CP and RY were supported by contracts from Ministerio de Ciencia e Innovación and Junta de Andalucía, respectively.

1. Wiley SR, Schooley K, Smolak PJ, Din WS, Huang CP, Nicholl JK et al. Identification and characterization of a new member of the TNF family that induces apoptosis. Immunity 1995; 3: 673-682.

2. Johnstone RW, Frew AJ, Smyth MJ. The TRAIL apoptotic pathway in cancer onset, progression and therapy. Nat Rev Cancer 2008; 8: 782-798.
3. Bodmer JL, Holler N, Reynard S, Vinciguerra P, Schneider P, Juo P et al. TRAIL receptor-2 signals apoptosis through FADD and caspase-8. Nat Cell Biol 2000; 2: 241-243.

4. Sprick MR, Weigand MA, Rieser E, Rauch $\mathrm{CT}$, Juo $\mathrm{P}$, Blenis $\mathrm{J}$ et al. FADD/MORT1 and caspase- 8 are recruited to TRAIL receptors 1 and 2 and are essential for apoptosis mediated by TRAIL receptor 2. Immunity 2000; 12: 599-609.

5. Irmler M, Thome M, Hahne M, Schneider P, Hofmann K, Steiner V et al. Inhibition of death receptor signals by cellular FLIP. Nature 1997; 388: 190-195.

6. Chang DW, Xing Z, Pan Y, Algeciras-Schimnich A, Barnhart BC, Yaish-Ohad S et al. c-FLIP $(\mathrm{L})$ is a dual function regulator for caspase-8 activation and CD95-mediated apoptosis. EMBO J 2002; 21: 3704-3714.

7. Krueger A, Schmitz I, Baumann S, Krammer PH, Kirchhoff S. Cellular FLICE-inhibitory protein splice variants inhibit different steps of caspase-8 activation at the CD95 deathinducing signaling complex. J Biol Chem 2001; 276: 20633-20640.

8. Pop C, Oberst A, Drag M, Van Raam BJ, Riedl SJ, Green DR et al. FLIP(L) induces caspase 8 activity in the absence of interdomain caspase 8 cleavage and alters substrate specificity. Biochem J 2011; 433: 447-457.

9. Kreuz S, Siegmund D, Scheurich P, Wajant H. NF-kappaB inducers upregulate cFLIP, a cycloheximide-sensitive inhibitor of death receptor signaling. Mol Cell Biol 2001; 21: 3964-3973.

10. Fukazawa T, Fujiwara T, Uno F, Teraishi F, Kadowaki $Y$, Itoshima $T$ et al. Accelerated degradation of cellular FLIP protein through the ubiquitin-proteasome pathway in p53-mediated apoptosis of human cancer cells. Oncogene 2001; 20: 5225-5231.

11. Citri A, Yarden Y. EGF-ERBB signalling: towards the systems level. Nat Rev Mol Cell Biol 2006; 7: 505-516.

12. Meloche S, Pouyssegur J. The ERK $1 / 2$ mitogen-activated protein kinase pathway as a master regulator of the G1- to S-phase transition. Oncogene 2007; 26: 3227-3239.

13. Gille $\mathrm{H}$, Kortenjann $\mathrm{M}$, Thomae $\mathrm{O}$, Moomaw $\mathrm{C}$, Slaughter $\mathrm{C}$, Cobb $\mathrm{MH}$ et al. ERK phosphorylation potentiates Elk-1-mediated ternary complex formation and transactivation. EMBO J 1995; 14: 951-962.

14. Murphy LO, Smith S, Chen RH, Fingar DC, Blenis J. Molecular interpretation of ERK signal duration by immediate early gene products. Nat Cell Biol 2002; 4: 556-564.

15. Okazaki K, Sagata N. The Mos/MAP kinase pathway stabilizes c-Fos by phosphorylation and augments its transforming activity in NIH 3T3 cells. EMBO J 1995; 14: 5048-5059.

16. Sears R, Leone G, DeGregori J, Nevins JR. Ras enhances Myc protein stability. Mol Cell 1999; 3: 169-179.

17. Normanno N, De Luca A, Bianco C, Strizzi L, Mancino M, Maiello MR et al. Epidermal growth factor receptor (EGFR) signaling in cancer. Gene 2006; 366: 2-16.

18. Baselga J, Arteaga CL. Critical update and emerging trends in epidermal growth factor receptor targeting in cancer. J Clin Oncol 2005; 23: 2445-2459.

19. Gibson EM, Henson ES, Haney N, Villanueva J, Gibson SB. Epidermal growth factor protects epithelial-derived cells from tumor necrosis factor-related apoptosisinducing ligand-induced apoptosis by inhibiting cytochrome $c$ release. Cancer Res 2002; 62: $488-496$.

20. Shrader M, Pino MS, Lashinger L, Bar-Eli M, Adam L, Dinney CP et al. Gefitinib reverses TRAIL resistance in human bladder cancer cell lines via inhibition of AKT-mediated X-linked inhibitor of apoptosis protein expression. Cancer Res 2007; 67: 1430-1435.

21. Barker AJ, Gibson KH, Grundy W, Godfrey AA, Barlow JJ, Healy MP et al. Studies leading to the identification of ZD1839 (IRESSA): an orally active, selective epidermal growth factor receptor tyrosine kinase inhibitor targeted to the treatment of cancer. Bioorg Med Chem Lett 2001; 11: 1911-1914.

22. Soule HD, Maloney TM, Wolman SR, Peterson WD Jr, Brenz R, McGrath CM et al. Isolation and characterization of a spontaneously immortalized human breast epithelial cell line, MCF-10. Cancer Res 1990; 50: 6075-6086.

23. Shankaran H, Ippolito DL, Chrisler WB, Resat H, Bollinger N, Opresko LK et al. Rapid and sustained nuclear-cytoplasmic ERK oscillations induced by epidermal growth factor. Mol Syst Biol 2009; 5: 332-344.

24. Palacios C, Yerbes R, Lopez-Rivas A. Flavopiridol induces cellular FLICE-inhibitory protein degradation by the proteasome and promotes TRAIL-induced early signaling and apoptosis in breast tumor cells. Cancer Res 2006; 66: 8858-8869.

25. Yerbes R, Palacios $C$, Reginato MJ, Lopez-Rivas A. Cellular FLIP(L) plays a survival role and regulates morphogenesis in breast epithelial cells. Biochim Biophys Acta 2011; 1813: 168-178.

26. Reginato MJ, Mills KR, Paulus JK, Lynch DK, Sgroi DC, Debnath J et al. Integrins and EGFR coordinately regulate the pro-apoptotic protein Bim to prevent anoikis. Nat Cell Biol 2003; 5: 733-740.

27. Eilers M, Eisenman RN. Myc's broad reach. Genes Dev 2008; 22: 2755-2766.

28. Cheng M, Wang D, Roussel MF. Expression of c-Myc in response to colony-stimulating factor-1 requires mitogen-activated protein kinase kinase-1. J Biol Chem 1999; 274: $6553-6558$

29. Ricci MS, Jin Z, Dews M, Yu D, Thomas-Tikhonenko A, Dicker DT et al. Direct repression of FLIP expression by c-myc is a major determinant of TRAIL sensitivity. Mol Cell Biol 2004; 24: $8541-8555$

30. Eilers M, Picard D, Yamamoto KR, Bishop JM. Chimaeras of myc oncoprotein and steroid receptors cause hormone-dependent transformation of cells. Nature 1989; 340: 66-68.

31. Littlewood TD, Hancock DC, Danielian PS, Parker MG, Evan GI. A modified oestrogen receptor ligand-binding domain as an improved switch for the regulation of heterologous proteins. Nucleic Acids Res 1995; 23: 1686-1690. 
32. Leone G, DeGregori J, Sears R, Jakoi L, Nevins JR. Myc and Ras collaborate in inducing accumulation of active cyclin E/Cdk2 and E2F. Nature 1997; 387: 422-426.

33. Haenssen KK, Caldwell SA, Shahriari KS, Jackson SR, Whelan KA, Klein-Szanto AJ et al. ErbB2 requires integrin alpha5 for anoikis resistance via Src regulation of receptor activity in human mammary epithelial cells. J Cell Sci 2010; 123: 1373-1382.

34. Ashkenazi A, Dixit VM. Apoptosis control by death and decoy receptors. Curr Opin Cell Biol 1999; 11: 255-260.

35. Walczak H, Miller RE, Ariail K, Gliniak B, Griffith TS, Kubin M et al. Tumoricidal activity of tumor necrosis factor-related apoptosis-inducing ligand in vivo. Nat Med 1999; 5: 157-163.

36. Grosse-Wilde A, Voloshanenko O, Bailey SL, Longton GM, Schaefer U, Csernok Al et al. TRAIL-R deficiency in mice enhances lymph node metastasis without affecting primary tumor development. J Clin Invest 2008; 118: 100-110.

37. Yee L, Burris $\mathrm{H}$, Kozloff $\mathrm{M}$ et al. Phase $1 \mathrm{~b}$ study of recombinant human APO2L/TRAIL plus irinotecan and cetuximab or FOLFIRI in metastatic colorectal cancer (mCRC) patients: preliminary results. J Clin Oncol (ASCO Meet Abstr) 2009; 27: 4129.

38. Mills KR, Reginato M, Debnath J, Queenan B, Brugge JS. Tumor necrosis factor-related apoptosis-inducing ligand (TRAIL) is required for induction of autophagy during lumen formation in vitro. Proc Natl Acad Sci USA 2004; 101: 3438-3443.

39. Bonni A, Brunet A, West AE, Datta SR, Takasu MA, Greenberg ME. Cell survival promoted by the Ras-MAPK signaling pathway by transcription-dependent and -independent mechanisms. Science 1999; 286: 1358-1362.

40. Cuello M, Ettenberg SA, Clark AS, Keane MM, Posner RH, Nau MM et al. Down-regulation of the erbB-2 receptor by trastuzumab (herceptin) enhances tumor necrosis factor-related apoptosis-inducing ligand-mediated apoptosis in breast and ovarian cancer cell lines that overexpress erbB-2. Cancer Res 2001; 61: 4892-4900.

41. Zhang XD, Borrow JM, Zhang XY, Nguyen T, Hersey P. Activation of ERK1/2 protects melanoma cells from TRAIL-induced apoptosis by inhibiting Smac/DIABLO release from mitochondria. Oncogene 2003; 22: 2869-2881.

42. Kadowaki Y, Chari NS, Teo AE, Hashi A, Spurgers KB, McDonnell TJ. PI3 kinase inhibition on TRAIL-induced apoptosis correlates with androgen-sensitivity and p21 expression in prostate cancer cells. Apoptosis 2011; 16: 627-635.

43. Frese S, Pirnia F, Miescher D, Krajewski S, Borner MM, Reed JC et al. PG490-mediated sensitization of lung cancer cells to Apo2L/TRAIL-induced apoptosis requires activation of ERK2. Oncogene 2003; 22: 5427-5435.

44. Shaw RJ, LC. Cantley LC. RasPI(3)K and mTOR signalling controls tumour cell growth. Nature 2006; 441: 424-430.

45. Marshall CJ. Specificity of receptor tyrosine kinase signaling: transient versus sustained extracellular signal-regulated kinase activation. Cell 1995; 80: 179-185.

46. Weaver VM, Lelievre S, Lakins JN, Chrenek MA, Jones JC, Giancotti F et al. beta4 integrindependent formation of polarized three-dimensional architecture confers resistance to apoptosis in normal and malignant mammary epithelium. Cancer Cell 2002; 2: 205-216.
47. Wang F, Weaver VM, Petersen OW, Larabell CA, Dedhar S, Briand $P$ et al. Reciprocal interactions between beta1-integrin and epidermal growth factor receptor in three-dimensional basement membrane breast cultures: a different perspective in epithelial biology. Proc Natl Acad Sci USA 1998; 95: 14821-14826.

48. Mendoza MC, Er EE, Blenis J. The Ras-ERK and PI3K-mTOR pathways: cross-talk and compensation. Trends Biochem Sci 2011; 36: 320-328.

49. Sears R, Nuckolls F, Haura E, Taya Y, Tamai K, Nevins JR. Multiple Ras-dependent phosphorylation pathways regulate Myc protein stability. Genes Dev 2000; 14: 2501-2514

50. Yada M, Hatakeyama S, Kamura T, Larabell CA, Dedhar S, Briand $P$ et al. Phosphorylation-dependent degradation of $\mathrm{C}-\mathrm{Myc}$ is mediated by the F-box protein Fbw7. EMBO J 2004; 23: 2116-2125.

51. Gibson SB. Epidermal growth factor and trail interactions in epithelial-derived cells. Vitam Horm 2004; 67: 207-227.

52. Zhang $\mathrm{X}$, Zhang L, Yang $\mathrm{H}$, Huang $\mathrm{X}$, Otu $\mathrm{H}$, Libermann TA et al. c-Fos as a proapoptotic agent in TRAlL-induced apoptosis in prostate cancer cells. Cancer Res 2007; 67: 9425-9434.

53. Xu K, Shu HK. EGFR activation results in enhanced cyclooxygenase-2 expression through p38 mitogen-activated protein kinase-dependent activation of the Sp1/Sp3 transcription factors in human gliomas. Cancer Res 2007; 67: 6121-6129.

54. Ganapathy M, Ghosh R, Jianping X, Zhang X, Bedolla R, Schoolfield J et al. Involvement of FLIP in 2-methoxyestradiol-induced tumor regression in transgenic adenocarcinoma of mouse prostate model. Clin Cancer Res 2009; 15: 1601-1611.

55. Chang L, Kamata H, Solinas G, Luo JL, Maeda S, Venuprasad K et al. The E3 ubiquitin ligase itch couples JNK activation to TNFalpha-induced cell death by inducing c-FLIP(L) turnover. Cell 2006; 124: 601-613.

56. Slamon DJ, Clark GM, Wong SG, Levin WJ, Ullrich A, McGuire WL. Human breast cancer: correlation of relapse and survival with amplification of the HER-2/neu oncogene. Science 1987; 235: 177-182.

57. Stagg J, Sharkey J, Pommey S, Young R, Takeda K, Yagita H et al. Antibodies targeted to TRAIL receptor-2 and ErbB-2 synergize in vivo and induce an antitumor immune response. Proc Natl Acad Sci USA 2008; 105: 16254-16259.

58. Dubska L, Andera L, Sheard MA. HER2 signaling downregulation by trastuzumab and suppression of the PI3K/Akt pathway: an unexpected effect on TRAIL-induced apoptosis. FEBS Lett 2005; 579: 4149-4158.

59. Nesterov A, Nikrad M, Johnson T, Kraft AS. Oncogenic Ras sensitizes normal human cells to tumor necrosis factor-alpha-related apoptosis-inducing ligand-induced apoptosis. Cancer Res 2004; 64: 3922-3927.

60. Ruiz-Ruiz C, Lopez-Rivas A. Mitochondria-dependent and -independent mechanisms in tumour necrosis factor-related apoptosis-inducing ligand (TRAIL)-induced apoptosis are both regulated by interferon-gamma in human breast tumour cells. Biochem J 2002; 365: 825-832. 